\title{
Introducing the magnetic properties in Fe doped ZnO nanoparticles for spintronics application
}

\section{Shradha Roy}

National Institute of Technology Patna

MRITUNJOY PRASAD GHOSH

National Institute of Technology Patna

Samrat Mukherjee ( $\nabla$ samrat.udc@gmail.com )

National Institute of Technology Patna https://orcid.org/0000-0002-5653-1244

Original Research

Keywords: Diluted magnetic semiconductor, ZnO nanoparticles, Williamson-Hall plots, Optical absorption, Magnetization

Posted Date: February 9th, 2021

DOI: https://doi.org/10.21203/rs.3.rs-180286/v1

License: (9) This work is licensed under a Creative Commons Attribution 4.0 International License. Read Full License 


\title{
Introducing the magnetic properties in Fe doped $\mathrm{ZnO}$ nanoparticles for spintronics application
}

\author{
Shradha Roy, Mritunjoy Prasad Ghosh, Samrat Mukherjee ${ }^{*}$ \\ Department of Physics, National Institute of Technology Patna, Patna-800005, Bihar, India \\ *Email: samrat.udc@gmail.com (Email of the corresponding author)
}

\begin{abstract}
Proper correlation among the microstructural, optical and magnetic responses of $\mathrm{Fe}$ doped $\mathrm{ZnO}$ nanoparticles have been established in this work. All the Fe doped $\mathrm{ZnO}$ nanoparticles $\left(\mathrm{Zn}_{1-\mathrm{x}} \mathrm{Fe}_{\mathrm{x}} \mathrm{O}: \mathrm{x}=\right.$ $0.00,0.05,0.10$ and 0.15 ) were prepared using chemical co-precipitation route. Average crystallites size of $18 \mathrm{~nm}$ to $28 \mathrm{~nm}$ was estimated using Scherrer's formula. Compressive microstrain was detected in pristine $\mathrm{ZnO}$ samples, which moved toward tensile regime upon introducing $\mathrm{Fe}$ ions of different weight percentages. Mean crystallites size obtained from Scherrer's formula was found in almost exact match with the particle size estimated from HRTEM images. Nearly spherical $\mathrm{ZnO}$ nanoparticles were seen in HRTEM images and negligible agglomeration among particles was also observed. Direct optical band gaps were found in the range of $2.89 \mathrm{eV}$ to $3.24 \mathrm{eV}$ as estimated from Tauc plots. A decent ferromagnetic signature in non-magnetic $\mathrm{ZnO}$ nanoparticles was also introduced at room temperature with the doping of Fe ions.
\end{abstract}

Key words: Diluted magnetic semiconductor; ZnO nanoparticles; Williamson-Hall plots; Optical absorption; Magnetization

\section{Introduction}

In the last decade, crucial efforts have been dedicated to synthesize and characterize semiconductor materials doped with transition metals. DMS materials show semiconducting as well as ferromagnetic properties at room temperature [1-4]. Transition metal (TM) doped semiconductors device used in the field of quantum computation, storage and communication devices and logic elements [5-8]. These materials can be termed as dilute magnetic semiconductor since a small proportion of transition metal can give drift to room temperature ferromagnetism. Theoretically, the presence of stable ferromagnetism is predicted in wide band gap semiconducting material [8-10]. The presence of room temperature ferromagnetism in $\mathrm{ZnO}$ attracted many researchers' interests in this area. Most of the results are questionable in nature and the magnetic ordering in wide band gap DMS are associated 
with defects and impurity phases. In a few cases, the absence of magnetic ordering has also been highlighted $[11,12]$. Synthesis methods play a major role in defining the magnetic ordering. Among these dilute magnetic semiconductor materials $\mathrm{ZnO}$ was observed as a potential candidate. $\mathrm{ZnO}$ is chemically and thermally stable n-type semiconductor. TM doped $\mathrm{ZnO}$ is a promising candidate due to its wide band gap $(3.3 \mathrm{eV})$, large exciton binding energy around $60 \mathrm{meV}$ and high carrier density [12-14].

In past few decades, researchers have tried to introduce magnetic signature in various non-magnetic metal oxide semiconductors [15-17]. Although partial doping of $3 \mathrm{~d}$ transition metal ions as well as $4 \mathrm{f}$ rare earth ions in non-magnetic nanosized $\mathrm{ZnO}$ showed a high possibility of observing magnetic properties at room temperature [12, 16-18]. In the development of new generation non-toxic advanced spintronics materials, transition metal (TM) ions doped $\mathrm{ZnO}$ has emerged as a promising candidate from the class of oxide based diluted magnetic semiconductors. Zinc oxide has been become the first choice of researchers due to its good piezoelectric effect, biomedical compatibilities and room temperature ferromagnetism [12]. The past decade records the attention of researchers from different fields on this material due its vast technical applications, such as in the field of chemical sensors, UVdetectors, semiconductor lasers of short wavelength, non-linear varistors and in semiconducting-based MEMS/NEMS technology $[12,14]$. Further enhancement of electrical conductivity for pristine $\mathrm{ZnO}$ can be done by doping with selected elements such as Ga [19, 20], Mn [17] and Al [21].

In this article, we have presented the synthesis and physical characterizations of ultrafine homogeneous $\mathrm{Fe}$ ions doped $\mathrm{ZnO}$ nanoparticles. Chemical co-precipitation method has been utilized to prepare all the samples. A decent magnetic signature in non-magnetic $\mathrm{ZnO}$ nanoparticles was also recorded at room temperature due to doping of Fe ions. A proper correlation among the structural, optical and magnetic responses of $\mathrm{Fe}$ doped $\mathrm{ZnO}$ nanoparticles has been established in this work.

\section{Experimental method}

\subsection{Synthesis of nanoparticles}

Fe doped $\mathrm{ZnO}$ nanoparticles with a generic formula $\mathrm{Zn}_{1-\mathrm{x}} \mathrm{Fe}_{\mathrm{x}} \mathrm{O}(\mathrm{x}=0.00,0.05,0.10$ and 0.15$)$ were fabricated using standard chemical co-precipitation method $[4,22]$. Raw chemicals $\mathrm{ZnCl}_{2}$ and $\mathrm{FeCl}_{2}$ were used for synthesizing nanoparticles. All the reagents were purchased from Merck having a purity level of $99.99 \%$ for $\mathrm{ZnCl}_{2}$ and $98 \%$ for $\mathrm{FeCl}_{2}$. All the chemicals were used without any purification. At first, all the glassware was washed with nitric acid, distilled water and acetone in that order to ensure that no trace of impurity would contaminate the sample via the glassware. $\mathrm{ZnCl}_{2}$ and $\mathrm{FeCl}_{2}$ were dissolved in $200 \mathrm{ml}$ of distilled water in stoichiometric ratio. $500 \mathrm{mg}$ PVP was added into the solution which acts as a binding agent. The solution was kept on a magnetic stirrer and rotated with a 
rate of $700 \mathrm{rpm}$ for homogeneous mixing. Precipitating agent $\mathrm{NaOH}$ solution was mixed in the form of droplets into the solution under continuous stirring. $\mathrm{NaOH}$ solution was added continuously with the same rate until the $\mathrm{pH}$ of the solution reached 12 to ensure no elements remain unreacted. After that, the precipitate was washed several times using distilled water and ethanol to reduce $\mathrm{pH}$ until 7. The precipitate was dried in an open atmosphere and then ground into the fine powder [23]. All the synthesized samples were indexed as Fe-00, Fe-05, Fe-10 and Fe-15. The prepared samples were kept safely in separate containers and were used for all the characterizations.

\subsection{Characterizations}

Confirmation regarding phase-purity and generation of hexagonal wurtzite structure was verified by diffraction profiles as obtained from Rigaku Ultima IV x-ray diffractometer with copper Ka line $(1.5406 \AA)$. Diffraction data were collected at room temperature in the range of $20^{\circ}$ to $80^{\circ}$ with a scan rate of 2 degrees per minute. Both the microstructure and morphology of synthesized nanoparticles were analyzed through high resolution transmission electron microscopy (HRTEM; JEOL, Japan). Absorption spectra of all samples were recorded between $200 \mathrm{~nm}$ to $800 \mathrm{~nm}$ at $300 \mathrm{~K}$ using ThermoScientific Evolution. Magnetic characterization of all Fe doped $\mathrm{ZnO}$ nanoparticles were carried out with the help of vibrating sample magnetometer (Quantum Design, VSM) at room temperature.

\section{Result and discussion}

\subsection{XRD pattern studies}

Room temperature powder diffraction pattern of all synthesized $\mathrm{Fe}$ doped $\mathrm{ZnO}$ nanoparticles are shown in figure 1. All the diffraction peaks were found to match exactly with JCPDS card no 890511. Diffraction profiles exhibited all characteristics peaks of pristine $\mathrm{ZnO}$ and were indexed with their Miller indices as (100), (002), (101), (102), (110) and (103) etc. The non-existence of any extra peak other than pure $\mathrm{ZnO}$ confirmed the phase purity and formation of the hexagonal wurtzite structure $[2,4]$. Rietveld analysis of all the diffraction patterns was performed using the general structure analysis system (GSAS) along with EXPGUI interface. The obtained values of cell parameters and refinement parameters are displayed in table 1 . All the diffracted peaks were shaped using the pseudo-Voigt function (superposition of Lorentzian and Gaussian function). Estimated values of reliability factors $\left(\mathrm{W}_{\mathrm{Rp}}\right.$ and $\mathrm{R}_{\mathrm{p}}$ ) below $10 \%$ along with decent goodness of fit $\left(\chi^{2}\right)$ verified a good agreement between obtained and standard experimental results [24]. The observed broadening in diffractograms ensured that the prepared samples were in the nano range. Ratio of lattice constants (c/a) was found close to 1.6 for all the samples which also verified the formation of hexagonal wurtzite structure as noticed in table 1 . 


\section{$\underline{\text { Scherrer's formula }}$}

The average crystallite size was calculated using Scherrer equation using full width at half maximum (FWHM) as follows [4]

$$
D=\frac{0.94 \lambda}{\beta_{d}} \cdot \frac{1}{\cos \theta}
$$

where $\lambda$ is wavelength $(1.5406 \dot{\mathrm{A}})$ of $\mathrm{Cu} \mathrm{K} \alpha$ line, $\mathrm{D}$ is the average particle size and $\beta_{\mathrm{d}}$ represents the FWHM value of (101) peak. The estimated values of average crystallite size were $18 \mathrm{~nm}, 22 \mathrm{~nm}, 26$ $\mathrm{nm}$ and $28 \mathrm{~nm}$ for Fe-00, Fe-05, Fe-10 and Fe-15 respectively. The obtained values of average crystallite size together with microstrain are given in table 2 .

\section{Williamson-Hall method}

Determination of average crystallite size from Scherrer formula does not take into account the contribution of intrinsic strain which develops in a nanocrystal due the presence of point defect, stacking faults, grain boundaries, etc. Williamson-Hall (W-H) method is one the approaches which has taken these contributions into account. Broadening of diffraction peaks is mainly due to three primary reasons i.e. crystallite size effect, microstrain and instrumental effect [24, 25]. Elimination of instrumental broadening was done by recording the diffraction pattern of bulk $\mathrm{LaB}_{6}$ powder. After removing the instrumental broadening, the total line width $(\beta)$ takes the form as [25]

$$
\begin{gathered}
\beta=\beta_{\text {crys }}+\beta_{\text {microstrain }} \\
\beta=\frac{K \lambda}{D \cos \theta}+4 \epsilon \tan \theta
\end{gathered}
$$

where $\beta$ is full-width half maxima, $K$ represents the geometrical factor ( 0.9 for spherical shaped particles), $\lambda$ signifies wavelength of $\mathrm{Cu} \mathrm{K}_{\alpha}$ line $(=1.5406 \AA$ ), D corresponds to the mean crystallite size, $\varepsilon$ addresses microstrain and $\theta$ is the Bragg's angle respectively. Rearranging the equation 3 , we get the known form as shown below [25]

$$
\beta \cos \theta=\frac{0.9 \lambda}{D \cos \theta}+4 \epsilon \sin \theta
$$

Separation of size and microstrain effects from total line width of diffracted peaks was done by plotting $\beta \cos \theta$ as a function of $4 \sin \theta$ which is familiar as the Williamson-Hall (W-H) graph as described in equation (4). The slope of this curve represents microstrain present inside the crystal and crystallite size was calculated from intercept on $\beta \cos \theta$ axis $[24,25]$. W-H plot of all the samples is presented in figure 2. The average crystallite size was found in the range of $14 \mathrm{~nm}-35 \mathrm{~nm}$ and negative value of microstrain for pristine $\mathrm{ZnO}$ sample also showed its compressive nature [24]. The estimated microstrain was gradually increased and becomes tensile in nature with increasing $\mathrm{Fe}$ content as seen from table 2 . This is due to the considerable mismatch in ionic radii of $\mathrm{Zn}^{2+}(0.60 \AA)$ 
ions and $\mathrm{Fe}^{2+}(0.63 \AA)$ ions. Determination of lattice parameter (a) is done using the following relation [19]

$$
\frac{1}{d^{2}}=\frac{4}{3}\left(\frac{h^{2}+h k+k^{2}}{a^{2}}\right)+\frac{l^{2}}{c^{2}}
$$

where $\mathrm{d}$ is the interplaner spacing and (hkl) denotes the Miller indices. Lattice parameter (a) was found to slightly decrease from pure $\mathrm{ZnO}$ values with increasing $\mathrm{Fe}^{2+}$ concentration. Calculated values of c/a ratio are minutely different from the standard value (1.633) for hexagonal wurtzite structure which confirmed the existence of structural deformation [26]. It is attributed to the nano-sized effect of prepared samples. A seen from table 1, the mass density is also observed to decrease with increasing Fe percentage in $\mathrm{ZnO}$ nanoparticles. It is due to the substitution of lighter $\mathrm{Fe}^{2+}$ ions in the position of $\mathrm{Zn}^{2+}$ ions.

\section{Halder-Wagner Method}

It is well known that the x-ray diffraction peaks are neither pure Gaussian or Lorentzian but rather a convolution of both as the peak region of the pattern matches well with Gaussian function but the tail region fails in matching and similar situation is observed in Lorentzian function in which matching is good at the tail region but not in the peak region. Halder-Wagner method overcomes this problem as it assumes peak broadening to be a symmetric Voigt function which is convolution of Gaussian and lorentzian function [27]. The method gives more weightage to peaks present in the range of low and intermediate angles where less overlapping of diffraction peaks takes place. Halder-Wagner method describes the relationship between the crystallite size and lattice strain as [27, 28]

$$
\left(\frac{\beta}{\tan \theta}\right)^{2}=\frac{k \lambda}{D} \cdot \frac{\beta}{\tan \theta \sin \theta}+16 \varepsilon^{2}
$$

The plot between $\left(\frac{\beta}{\tan \theta}\right)^{2}$ (y-axis) and $\frac{\beta}{\tan \theta \sin \theta}$ (x-axis) is a straight line whose slope provides average particle size and intercept provides the value of microstrain [28]. The H-W plot of all the synthesized samples is shown in figure 3. The average crystallite sizes of all samples containing nanoparticles were found within the range of $15 \mathrm{~nm}$ to $29 \mathrm{~nm}$. The mean diameter of all nanoparticles was increased with increasing Fe percentage in pure $\mathrm{ZnO}$. The obtained values of crystallite size and microstain are listed in table 2. The microstain for pristine $\mathrm{ZnO}$ nanoparticles was also found in compressive character which was in perfect match with the value obtained from WH plot. The microstrain also changed into tensile type in similar fashion with the increase of Fe concentration as observed from WH plot. 


\subsection{HRTEM image analysis}

HRTEM images of Fe-00 and Fe-10 samples are illustrated in figure 4(a) and 4(b) respectively. All the nanoparticles were appeared to be nearly spherical in shape. Excellent homogeneity in both size and shape was achieved as verified by HRTEM micrographs [2, 8]. An average particle size of $17 \pm 1$ $\mathrm{nm}$ was obtained for the pristine $\mathrm{ZnO}$ (Fe-00) sample, which is a close match with XRD results. A considerable agglomeration among the synthesized nanoparticles was observed which may be attributed to the Van der Waal interactions [25].

\subsection{UV-vis spectra studies}

Room temperature absorption spectra of all Fe doped $\mathrm{ZnO}$ nanoparticles were collected within the range of $200 \mathrm{~nm}$ to $800 \mathrm{~nm}$ using UV-Vis spectroscopy. Bulk ZnO consists of direct optical band gap at higher energy $(\approx 3.3 \mathrm{eV})[29]$. The direct band gap of prepared samples can be obtained using Tauc relationship as follows [24]

$$
\alpha(v) h v=B\left(h v-E_{o p}\right)^{n}
$$

where $\alpha$ is an absorption coefficient, $B$ represents an arbitrary constant, $E_{o p}$ corresponds to the optical band gap and $n$ denotes an index which attains values of $1 / 2$ for direct bandgap and 2 for indirect band gap semiconductor. The value of $\alpha$ is calculated using this general formula [23, 24]

$$
I=I_{0} e^{-\alpha t} \quad \text { and } \quad A=\log \left(\frac{I_{0}}{I}\right)
$$

where ' $\mathrm{A}$ ' is absorbance and ' $\mathrm{t}$ ' indicates the thickness of materials. The absorption coefficient $\alpha$ takes the form [24]

$$
\alpha=2.303\left(\frac{A}{t}\right)
$$

A graph between $(\alpha h v)^{2}$ versus $h v$ was plotted to obtain the direct optical band gap of all samples which is well known as Tauc plot [23]. Figure 5 represents the Tauc plots of all Fe doped $\mathrm{ZnO}$ samples. The estimated values of band gap for all Fe doped $\mathrm{ZnO}$ samples are collected in table 3 . The band gap was found to decrease with increasing Fe concentration in $\mathrm{ZnO}$ nanoparticles. Bulk $\mathrm{ZnO}$ displayed direct optical band gap of $3.3 \mathrm{eV}$ whereas our synthesized pristine $\mathrm{ZnO}$ nanoparticles exhibit a band gap of $3.24 \mathrm{eV}$. All the materials displayed band edge absorption within the range of $385 \mathrm{~nm}$ to $430 \mathrm{~nm}$. These materials can be used to absorb UV and violet bands of the electromagnetic spectrum along with various optical applications. 


\subsection{Magnetic studies}

Figure 6 depicts the magnetic hysteresis $(\mathrm{M}-\mathrm{H})$ curves registered at room temperature of all the samples. Due to the absence of unpaired ' $\mathrm{d}$ ' electrons, the pristine $\mathrm{ZnO}$ in bulk form exhibits diamagnetic behavior [30]. In nanoscale, the existence of several defect states together with a certain correlation among them induces weak ferromagnetism or paramagnetism in pure $\mathrm{ZnO}$ sample [12]. Defects driven weak ferromagnetism or paramagnetism in pure $\mathrm{ZnO}$ nanoparticles have been reported in many articles [31-33]. Room temperature ferromagnetism in nanosized $\mathrm{ZnO}$ semiconductor can be introduced by the doping with 3d transition metals like Mn, Fe, V, Co, Ni and Cr. Among of ' $3 \mathrm{~d}$ ' transition metal ions, Fe ions exhibit comparatively high magnetic moment as well as ferromagnetic character at room temperature $[2,5,34]$. Doping of $\mathrm{Fe}$ ions in pure $\mathrm{ZnO}$ nanoparticles should be convenient for observing ferromagnetism at room temperature. Usually the magnetic moment of $\mathrm{Fe}^{2+}$ $\left(5.4 \mu_{\mathrm{B}}\right)$ dopants inside the host $\mathrm{ZnO}$ semiconductor is localized. In case of dilute magnetic semiconductors, the interactions between localized magnetic moment of $\mathrm{Fe}^{2+}\left(3 \mathrm{~d}^{6}\right)$ ions and host semiconductor $(\mathrm{ZnO})$ determine the magnetic behavior of the system. As noticed from figure 6 , the pristine $\mathrm{ZnO}$ nanoparticles displayed paramagnetic behavior at room temperature which is quite obvious in nanosized $\mathrm{ZnO}$ sample. Observation of this type of behavior is attributed to the presence of various defect states in the sample. With the increase of $\mathrm{Fe}$ ions concentration in nanosized $\mathrm{ZnO}$, weak ferromagnetic character became more prominent $[2,5]$. An attentive observation of figure 6 disclosed that the hysteresis curves of all doped samples were unsaturated even in $30 \mathrm{kOe}$ magnetic field. The saturation magnetization $\left(\mathrm{M}_{\mathrm{S}}\right)$ of all doped samples was estimated using $\mathrm{M}$ vs $1 / \mathrm{H}$ plot (as $\left.1 / \mathrm{H} \rightarrow 0, \mathrm{M} \rightarrow \mathrm{M}_{\mathrm{S}}\right)$. The estimated values of coercivity $\left(\mathrm{H}_{\mathrm{C}}\right)$ and saturation magnetization $\left(\mathrm{M}_{\mathrm{S}}\right)$ are listed in table 4. Coercive field $\left(\mathrm{H}_{\mathrm{C}}\right)$ together with saturation magnetization $\left(\mathrm{M}_{\mathrm{S}}\right)$ was noticed to increase in doped samples with respect to pristine $\mathrm{ZnO}$ sample.

In $3 \mathrm{~d}$ transition metal magnetic $\left(\mathrm{Fe}^{2+}\right)$ ions doped pristine $\mathrm{ZnO}$ nanocrystals; $\mathrm{p}-\mathrm{d}$ exchange interactions are responsible for the emergence of weak ferromagnetic behavior at room temperature. Both the bond length and bond angle between $\mathrm{Zn}^{2+}$ ions/dopant cations and $\mathrm{O}^{2-}$ anions favor the $\mathrm{p}-\mathrm{d}$

hybridization in $\mathrm{ZnO}$ crystal system. In tetrahedral co-ordinated environment, the degenerate $3 \mathrm{~d}$ ground state of $\mathrm{Fe}$ ion splits in to $\mathrm{t}_{2 \mathrm{~g}}$ levels and $\mathrm{e}_{\mathrm{g}}$ levels due to presence of crystal field. The $\mathrm{t}_{2 \mathrm{~g}}$ levels are energetically higher with respect to $e_{g}$ levels for tetrahedral co-ordinated sites. The crystal field splitting energy of $t_{2 g}$ and $e_{g}$ levels is relatively lower compared to the Coulomb interaction or pairing energy in host $\mathrm{ZnO}$ matrix, which favors the high spin configuration. The valance band of host $\mathrm{ZnO}$ (i.e. $3 p$ levels of $\mathrm{O}^{2-}$ ions) is energetically comparable with the $3 \mathrm{~d}$ levels ( $\mathrm{t}_{2 \mathrm{~g}}$ and $\mathrm{e}_{\mathrm{g}}$ ) of Fe ions which results in strong $\mathrm{p}-\mathrm{d}$ hybridization. The $\mathrm{p}$ - $\mathrm{d}$ hybridization between incomplete $3 \mathrm{~d}$ levels of transition metals (Fe ions) and host valence band gives rise to magnetic interactions. Fe ions in $\mathrm{ZnO}$ matrix exist in two different oxidation states i.e. $\mathrm{Fe}^{2+}$ and $\mathrm{Fe}^{3+}$ states. Due to the $\mathrm{p}$-d hybridization between $\mathrm{Fe}$ ions 
and valance band ( $2 \mathrm{p}$ levels of $\mathrm{O}^{2-}$ ions) of host $\mathrm{ZnO}$, hopping of electron is possible. Therefore, magnetic interactions are mediated by the hopping of electrons between Fe ions having oxidation states differ by one unit. This mechanism leads to ferromagnetic coupling of Fe ions in the host $\mathrm{ZnO}$ matrix $[22,35]$. For this reason, the entire Fe ions doped $\mathrm{ZnO}$ samples showed weak ferromagnetism at room temperature. Wurtzite $\mathrm{ZnO}$ naturally displays n-type semiconducting nature due to intrinsic vacancies. Generally n-type $\mathrm{ZnO}$ nanoparticles are readily available and several intrinsic defects ( $\mathrm{Zn}$ vacancies) also lead to arrival of high $\mathrm{T}_{\mathrm{C}}$ ferromagnetism. Slow incorporation of magnetic cations (Fe ions) in nanosized $\mathrm{ZnO}$ favored the sp-d or $\mathrm{p}$-d hybridization and also resulted in weak ferromagnetism at $300 \mathrm{~K}[10,22]$. The nanosized $\mathrm{ZnO}$ sample doped with $15 \% \mathrm{Fe}$ ions showed highest value of coercive field (101 Oe). All the Fe doped nanocrystalline $\mathrm{ZnO}$ samples exhibited week ferromagnetic nature at room temperature as verified by hysteresis loops.

\section{Conclusion}

In brief, we have successfully fabricated diluted magnetic semiconductor $\mathrm{Zn}_{1-\mathrm{x}} \mathrm{Fe}_{\mathrm{x}} \mathrm{O}(\mathrm{x}=0.00,0.05$, 0.10 and 0.15 ) nanoparticles by using chemical co-precipitation technique. Generation of pure hexagonal wurtzite crystal structure of all Fe doped $\mathrm{ZnO}$ nanoparticles were verified by x-ray diffractograms. Mean crystallite sizes of all samples were calculated using Scherrer's formula, Williamson-Hall (W-H) plot and Halder-Wagner (H-W) Method. A correlation among these methods was established. All these methods suggested that the synthesized $\mathrm{ZnO}$ nanoparticles were in nanoregime with mean crystallite size below $35 \mathrm{~nm}$. A compressive microstain was found for pristine $\mathrm{ZnO}$ sample and with increasing Fe ions content, the microstain became tensile in nature. This is due to the considerable mismatch in ionic radii of $\mathrm{Zn}^{2+}(0.6 \AA)$ ions and $\mathrm{Fe}^{2+}(0.63 \AA) / \mathrm{Fe}^{3+}(0.645 \AA)$ ions. Average particle diameter as estimated from HRTEM micrographs was observed in perfect harmony with crystallite size. The optical band gap was decreased with increasing Fe concentration in $\mathrm{ZnO}$ nanoparticles. All the synthesized materials showed band edge absorption within the range of $385 \mathrm{~nm}$ to $430 \mathrm{~nm}$ which makes all the materials useful to block UV and violet bands of the electromagnetic spectrum. Room temperature hysteresis loops of doped samples exhibited weak ferromagnetic character. This observed ferromagnetism in Fe doped $\mathrm{ZnO}$ nanocrystals can be tuned and enhanced with varying concentration below percolation limit.

\section{Author contribution statement}

All the authors contributed equally in this work.

\section{Declaration of interests}

Authors declare that they have no known competing financial interests or personal relationships that could have appeared to influence the work reported in this paper. 


\section{References}

[1] D. C. Look, G. C. Farlow, P. Reunchan, S. Limpijumnong, S. B. Zhang, K. Nordlund, Phys. Rev. Lett. 95, 225502 (2005).

[2] X. Wu, Z. Wei, L. Zhang, X. Wang, H. Yang, J. Jiang, J. Nanomaterials 2014, 792102 (2014).

[3] C. Klingshirn, Phys. Stat. Sol. b 244, 3027-3073 (2007).

[4] M. S. Inpasalini, P. V. Rajesh, D. Das, S. Mukherjee, J. Mater Sci.: Mater. Electron. 26, 10531059 (2015).

[5] T. A. Abdel-Baset, Y. W. Fang, B. Anis, C. G. Duan, M. Abdel-Hafiez, Nanoscale Res. Lett. 11(115), 1-12 (2016).

[6] S. J. Pearton, C. R. Abernathy, M. E. Overberg, G. T. Thaler, D. P. Norton, N. Theodoropoulou, A. F. Hebard, Y. D. Park, F. Ren, J. Kim, J. Appl. Phys. 93, 1 (2003).

[7] P. Sharma, K. Sreenivas, K. V. Rao, J. Appl. Phys. 93, 3963 (2003).

[8] B. Poornaprakash, U. Chalapathi, M. Kumar, P. T. Poojitha, J. Mater. Sci.: Mater. Electron. 29, 2316-2321 (2018).

[9] S. J. Han, J. W. Song, C. W. Yang, S. H. Park, J. H. Park, Y. H. Jeong, K. W. Rhie, Appl. Phys. Lett. 81(22), 4212-4214 (2002).

[10] G. Srinet, S. Sharma, J. G. Sanchez, R. G. Diaz, R. P. Perez, J. M. Siqueiros, O. R. Herrera, J. Alloy. Compd. 489, 156587 (2020).

[11] A. Janotti, C. G. Van de Walle, Rep. Prog. Phys. 72, 126501 (2009).

[12] H. Morkoc, U. Ozgur, Zinc Oxide: Fundamentals, Materials and Device Technology (WileyVCH) (2009).

[13] Ü. Özgür, Ya. I. Alivov, C. Liu, A. Teke, M. A. Reshchikov, S. Doğan, V. Avrutin, S. J. Cho, H. Morkoç, J. Appl. Phys. 98, 041301 (2005).

[14] O. Madelung, Data in Science and Technology: Semiconductors (Springer, Berlin) (1992).

[15] O. D. Jayakumar, C. Sudakar, C. Persson, H. G. Salunke, R. Naik, A. K. Tyagi, Appl. Phys. Lett. 97, 232510 (2010).

[16] K. Sato, H. K. Yoshida, Jpn. J. Appl. Phys., 40, L334-L336 (2001).

[17] T. Fukumura Z. Jin, A. Ohtomo, H. Koinuma, M. Kawasaki, Appl. Phys. Lett. 75, 3366-3368 (1999).

[18] S. A. Aravindh, U. Schwingenschloegl, I. M. Roqan, J. Appl. Phys. 116, 233906 (2014).

[19] M. C. Jun, S. U. Park, J. H. Koh, Nanoscale Res. Lett. 7, 639 (2012).

[20] A. K. Zak, N. S. A. Aziz, A. M. Hashim, F. Kardi, Ceram. Int. 42(12), 13605 (2016).

[21] M. Ohtaki, T. Tsubota, K. Eguchi, H. Arai, J. Appl. Phys. 79, 1816 (1996).

[22] S. Gupta, R. K. Choubey, L. K. Sharma, M. P. Ghosh, M. Kar, S. Mukherjee, Semiconductor. Sci. Tech. 34, 105006 (2019).

[23] M. P. Ghosh, S. Kinra, D. Dagur, R. K. Choubey, S. Mukherjee, Phys. Scr. 95, 095812 (2020).

[24] M. P. Ghosh, S. Mukherjee, J. Magn. Magn. Mater. 498, 166185 (2020). 
[25] M. P. Ghosh, S. Mukherjee, J. Am. Ceram. Soc. 102, 7509-7520 (2019).

[26] B. D. Cullity, Elements of X-ray diffraction (Addison-Wesley Publications) (1956).

[27] D. Nath, F. Singh, R. Das, Mater. Chem. Phys. 239, 122021 (2020).

[28] F. Izumi, T. Ikeda, Annual. Rep. Advan. Ceram. Res. 3, 33-38 (2015).

[29] Z. L.Wang, Mater. Today, 7, 26-33 (2004).

[30] B. Qi, S. Olafsson, H. P. Gislason, Progress. Mater. Sci. 90, 45-74 (2017).

[31] X. Zhang, W. Zhang, X. Zhang, X. Wu, F. Meng, C. C. Tang, Advan. Conden. Matter. Phys. 2014, 806327 (2014).

[32] G. Z. Xing, Y. H. Lu, Y. F. Tian, J. B. Yi, C. C. Lim, Y. F. Li, G. P. Li, D. D. Wang, B. Yao, J. Ding, Y. P. Feng, T. Wu, AIP Advan. 1, 022152 (2011).

[33] Deepika, R. Kumar, R. Kumar, K. P. Yadav, P. Vaibhav, S. Sharma, R. K. Singh, S. Kumar, Chinese. Phys. B 29, 108503 (2020).

[34] D. Karmakar, S. K. Mandal, R. M. Kadam, P. L. Paulose, A. K. Rajaranjan, T. K. Nath, A. K. Das, I. Dasgupta, G. P. Das, Phys. Rev. B 75, 144404 (2007).

[35] R. Shahid, M. Toprak, H. Soliman, M. Muhammed, Open. Chem. 10, 54-81 (2012).

\section{List of tables}

Table 1: Contains lattice parameters and Rietveld refinement factors of all the samples.

Table 2: Contains crystallite sizes and microstrain of all the samples.

Table 3: Represents direct optical band gaps of all the samples.

Table 4: Represents various magnetic parameters at $300 \mathrm{~K}$ for all the samples.

\section{List of figures}

Figure 1: Fitted $\mathrm{XRD}$ profiles of $\mathrm{Zn}_{1-\mathrm{x}} \mathrm{Fe}_{\mathrm{x}} \mathrm{O}(\mathrm{x}=0.00,0.05,0.10$ and 0.15$)$ samples.

Figure 2: Williamson-Hall (W-H) plots of all the samples.

Figure 3: H-W plots of all the samples.

Figure 4(a): HRTEM image of Fe-00 sample.

Figure 4(b): HRTEM image of Fe-10 sample.

Figure 5: Tauc plot of all the samples.

Figure 6: Room temperature M-H plots of all the samples. 


\begin{tabular}{|l|l|l|l|l|}
\hline Sample Id & Fe-00 & Fe-05 & Fe-10 & Fe-15 \\
\hline Lattice parameters & P63mc & P63mc & P63mc & P63mc \\
\hline Space group & 47.64 & 47.76 & 47.79 & 47.78 \\
\hline Volume $\left(\AA^{3}\right)$ & 17.02 & 16.92 & 16.82 & 16.74 \\
\hline$\rho\left(\mathrm{g} / \mathrm{cm}^{3}\right)$ & 3.250 & 3.250 & 3.249 & 3.248 \\
\hline$a=b(\AA)$ & 5.207 & 5.206 & 5.207 & 5.205 \\
\hline$c(\AA)$ & 1.602 & 1.601 & 1.602 & 1.602 \\
\hline$c / a$ & 90 & 90 & 90 \\
\hline$\alpha=\beta($ degree $)$ & 90 & 120 & 120 & 120 \\
\hline$\gamma($ degree $)$ & 120 & \multicolumn{5}{l|}{} \\
\hline Refinement factors & 7.78 & 6.27 & 6.17 & 5.07 \\
\hline \multicolumn{6}{|l}{$W_{R p}(\%)$} & 7.05 & 7.47 & 6.69 \\
\hline$R_{p}(\%)$ & 5.97 & 2.98 & 2.27 & \\
\hline$\chi^{2}$ & 2.29 & &
\end{tabular}

Table 1

\begin{tabular}{|l|l|l|l|l|l|}
\hline Sample Id & $\begin{array}{l}\text { Crystallite } \\
\text { size }(\mathrm{nm}) \\
\text { using Scherrer } \\
\text { formula }\end{array}$ & $\begin{array}{l}\text { Crystallite size } \\
(\mathrm{nm}) \\
\text { using WH plot }\end{array}$ & $\begin{array}{l}\text { Crystallite size } \\
(\mathrm{nm}) \\
\text { using HW plot }\end{array}$ & $\begin{array}{l}\text { Strain } \\
(\mathrm{x} \mathrm{10}) \\
\text { using WH plot }\end{array}$ & $\begin{array}{l}\text { Strain } \\
\left(\mathrm{x} \mathrm{10} 0^{-3}\right) \\
\text { using HW Plot }\end{array}$ \\
\hline Fe-00 & 18 & 14 & 15 & -0.68 & -1.25 \\
\hline Fe-05 & 22 & 21 & 20 & 0.49 & 1.04 \\
\hline Fe-10 & 26 & 33 & 27 & 1.72 & 2.14 \\
\hline Fe-15 & 28 & 35 & 29 & 1.83 & 2.23 \\
\hline
\end{tabular}

Table 2

\begin{tabular}{|l|c|}
\hline Sample-Id & Band gap (eV) \\
\hline Fe-00 & 3.24 \\
\hline Fe-05 & 3.04 \\
\hline Fe-10 & 3.01 \\
\hline Fe-15 & 2.89 \\
\hline
\end{tabular}

Table 3

\begin{tabular}{|c|c|c|}
\hline \multirow{2}{*}{ Sample-Id } & \multicolumn{2}{|c|}{ Magnetic properties } \\
\cline { 2 - 3 } & $\mathrm{H}_{\mathrm{C}}(\mathrm{Oe})$ & $\mathrm{M}_{\mathrm{S}}(\mathrm{emu} / \mathrm{g})$ \\
\hline $\mathrm{Fe}-00$ & 12 & 0.03 \\
\hline $\mathrm{Fe}-05$ & 81 & 0.21 \\
\hline $\mathrm{Fe}-10$ & 96 & 0.39 \\
\hline $\mathrm{Fe}-15$ & 101 & 0.54 \\
\hline
\end{tabular}

Table 4 

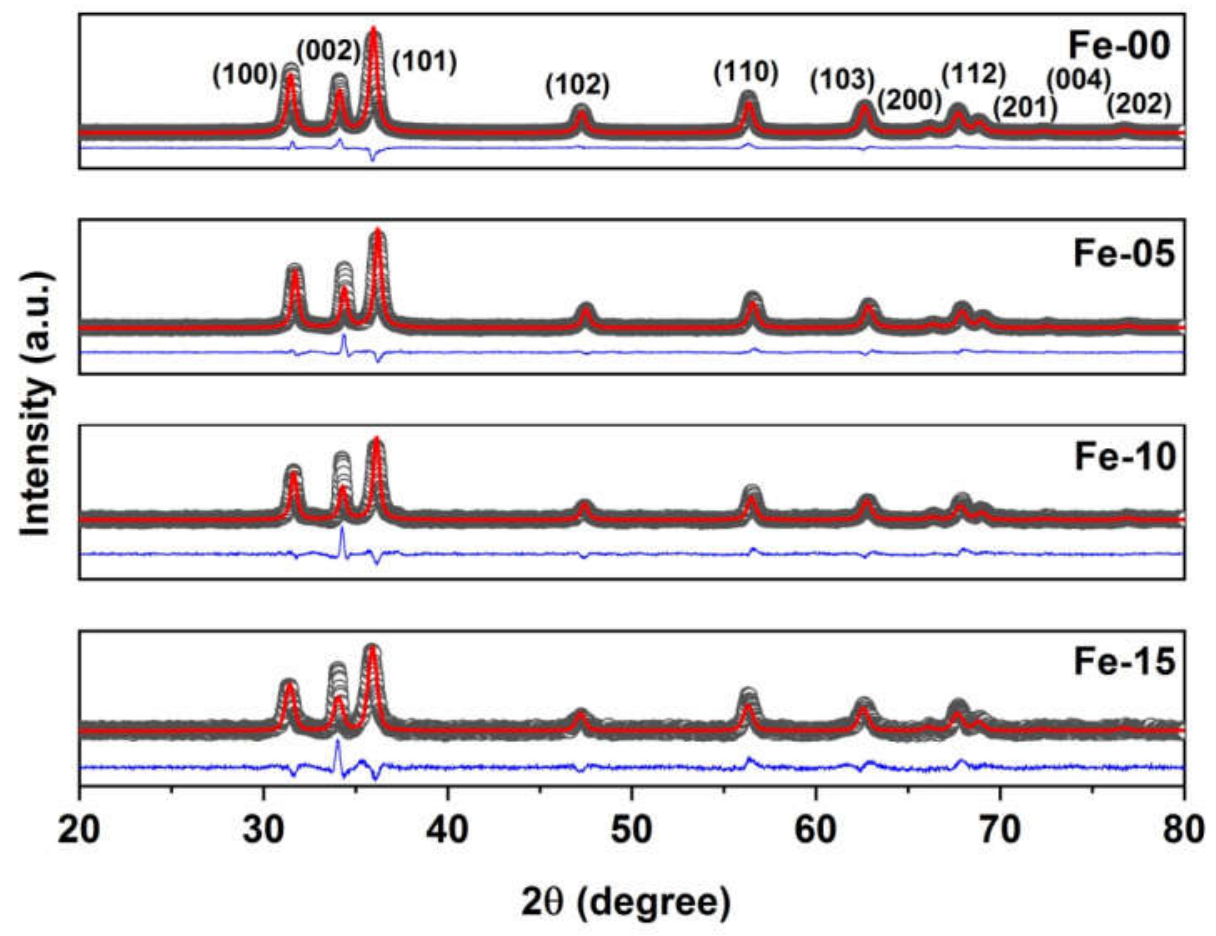

Figure 1

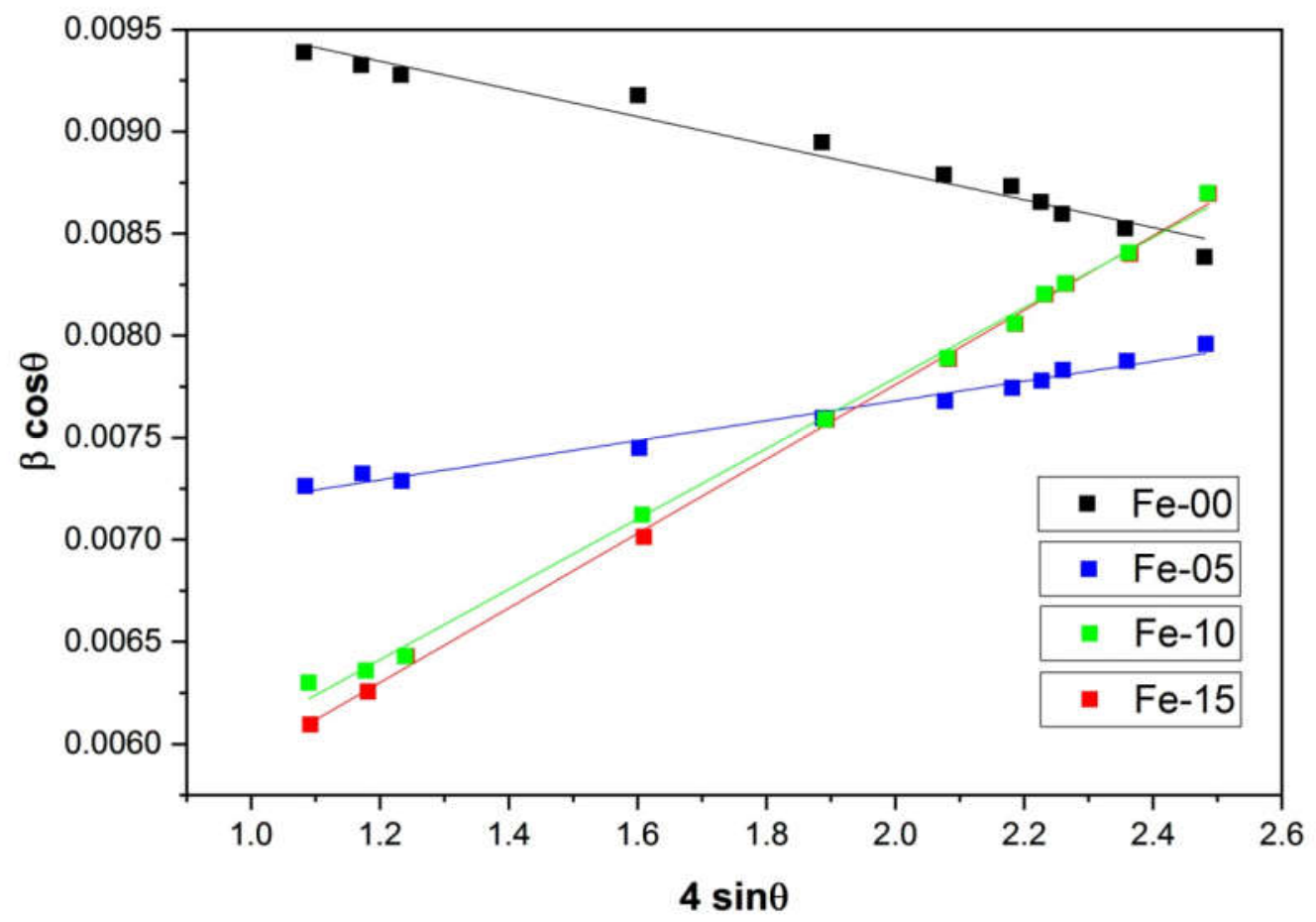

Figure 2 


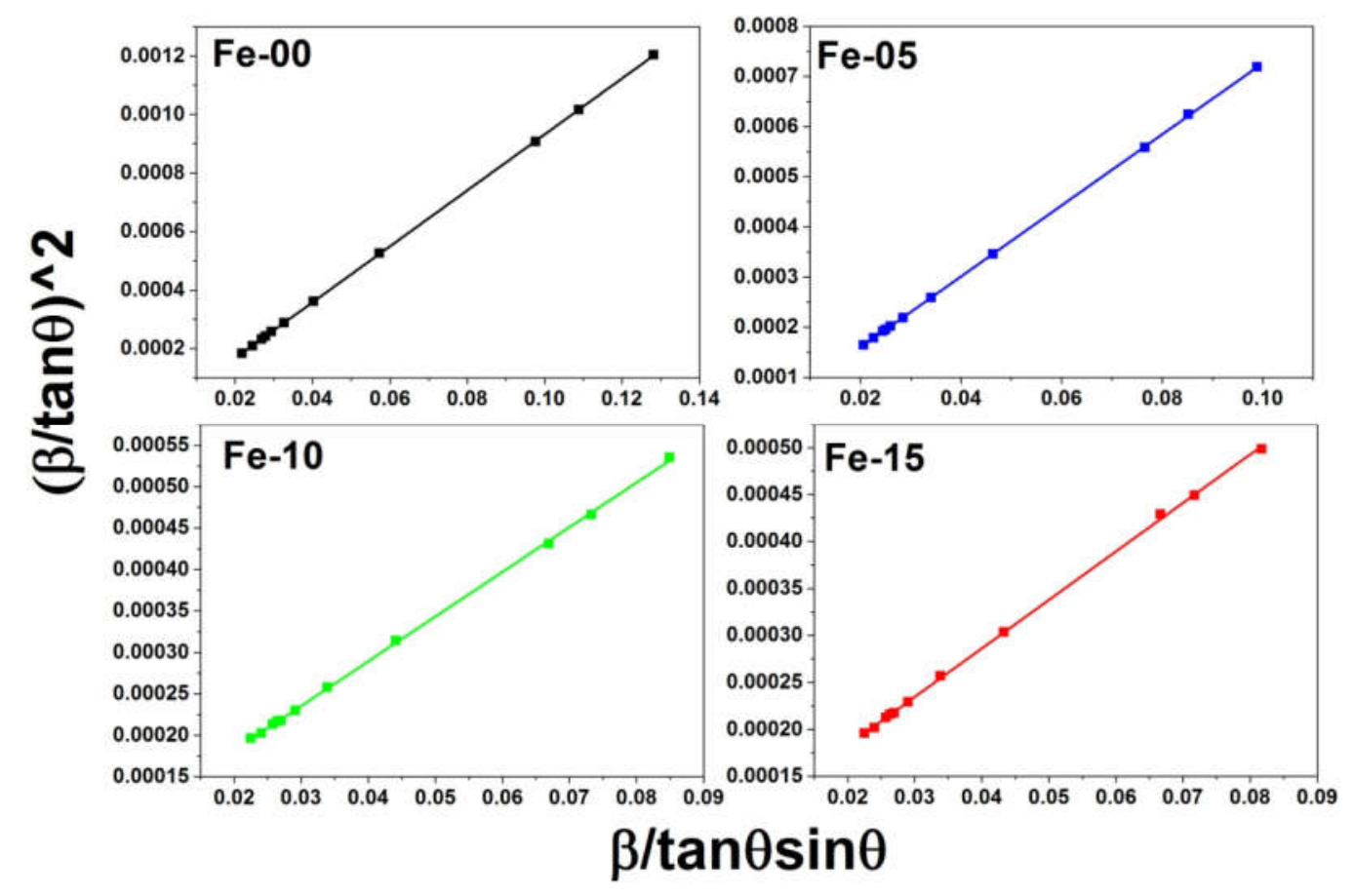

Figure 3 


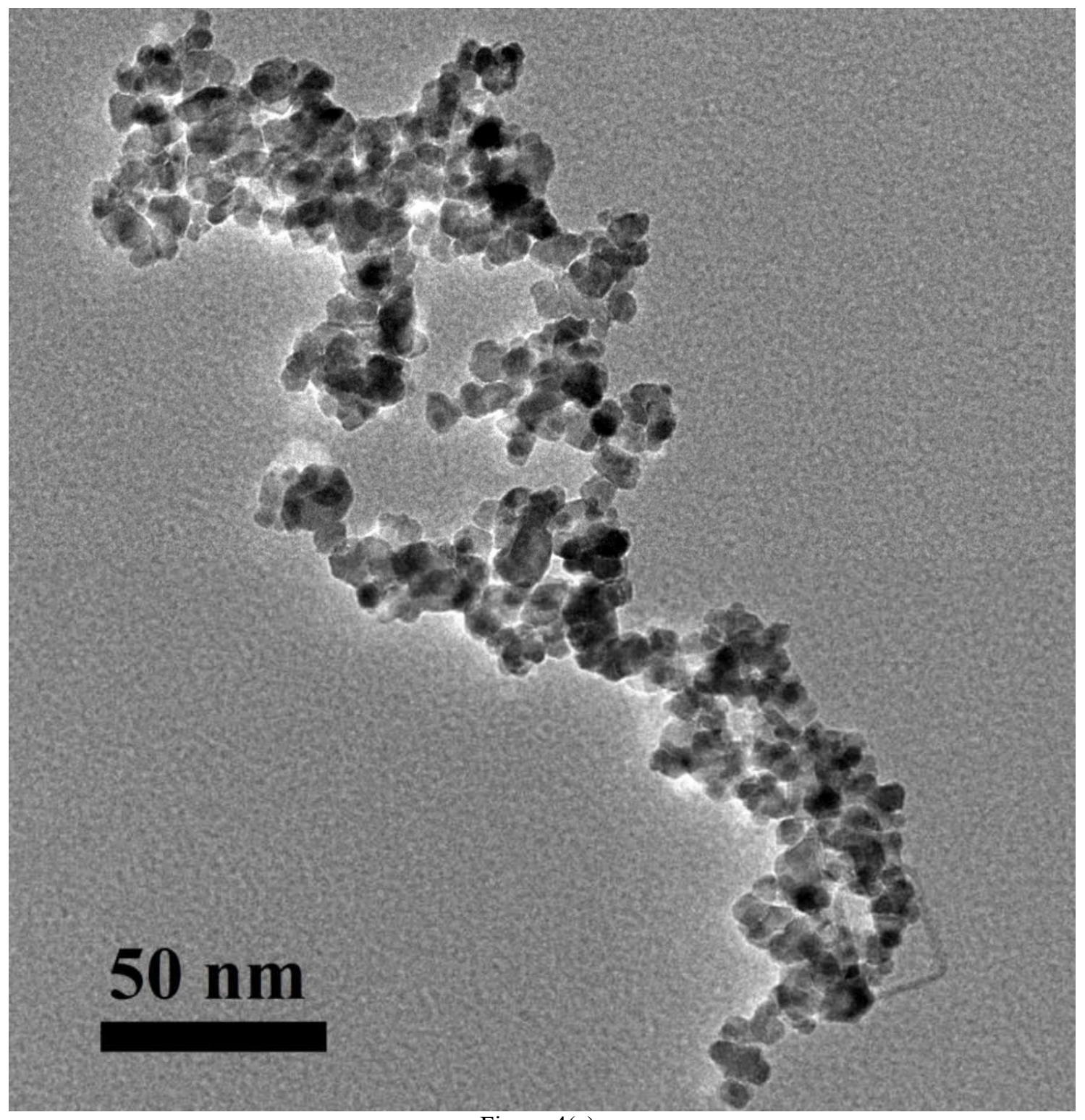

Figure 4(a) 


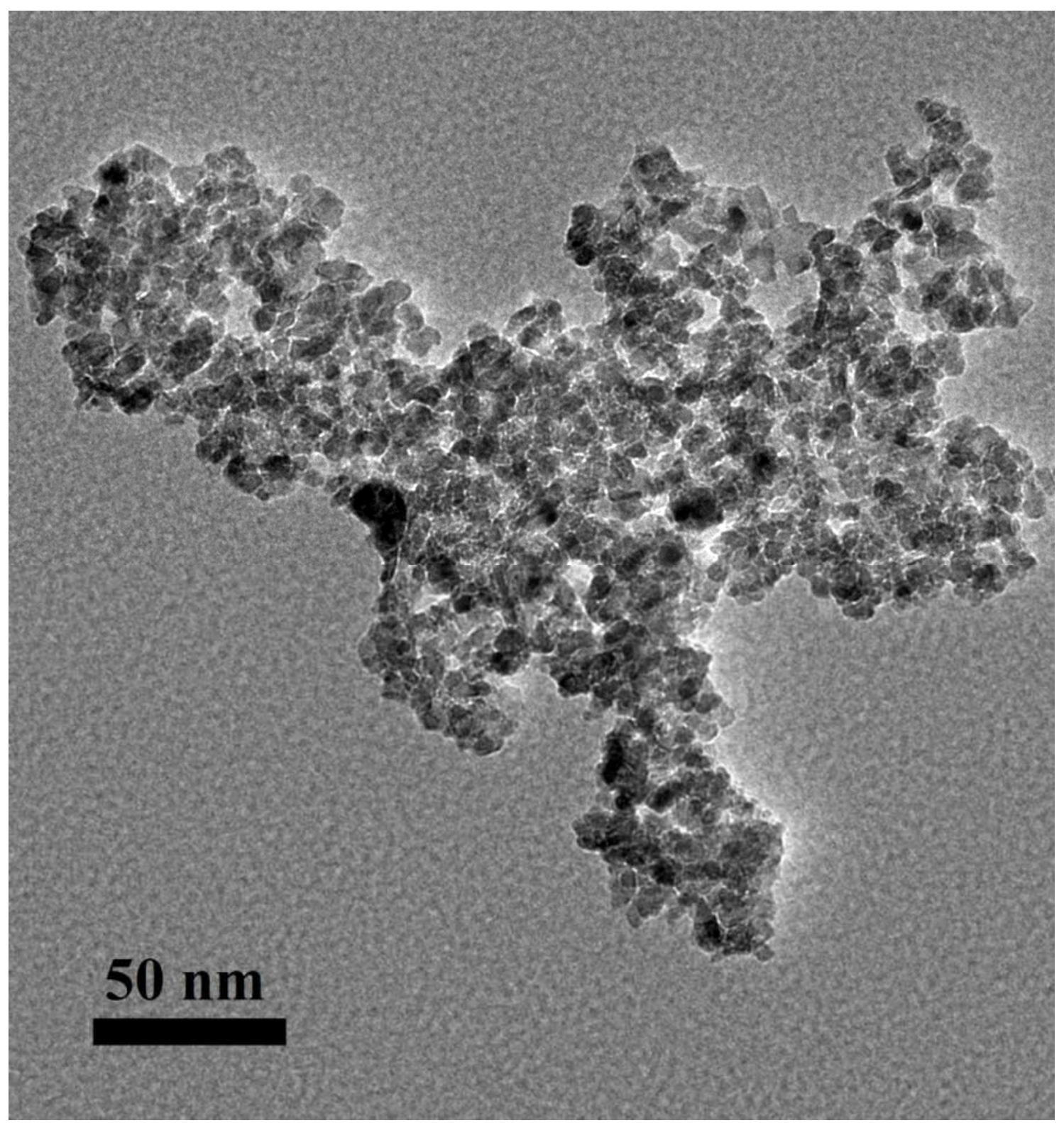

Figure 4(b) 


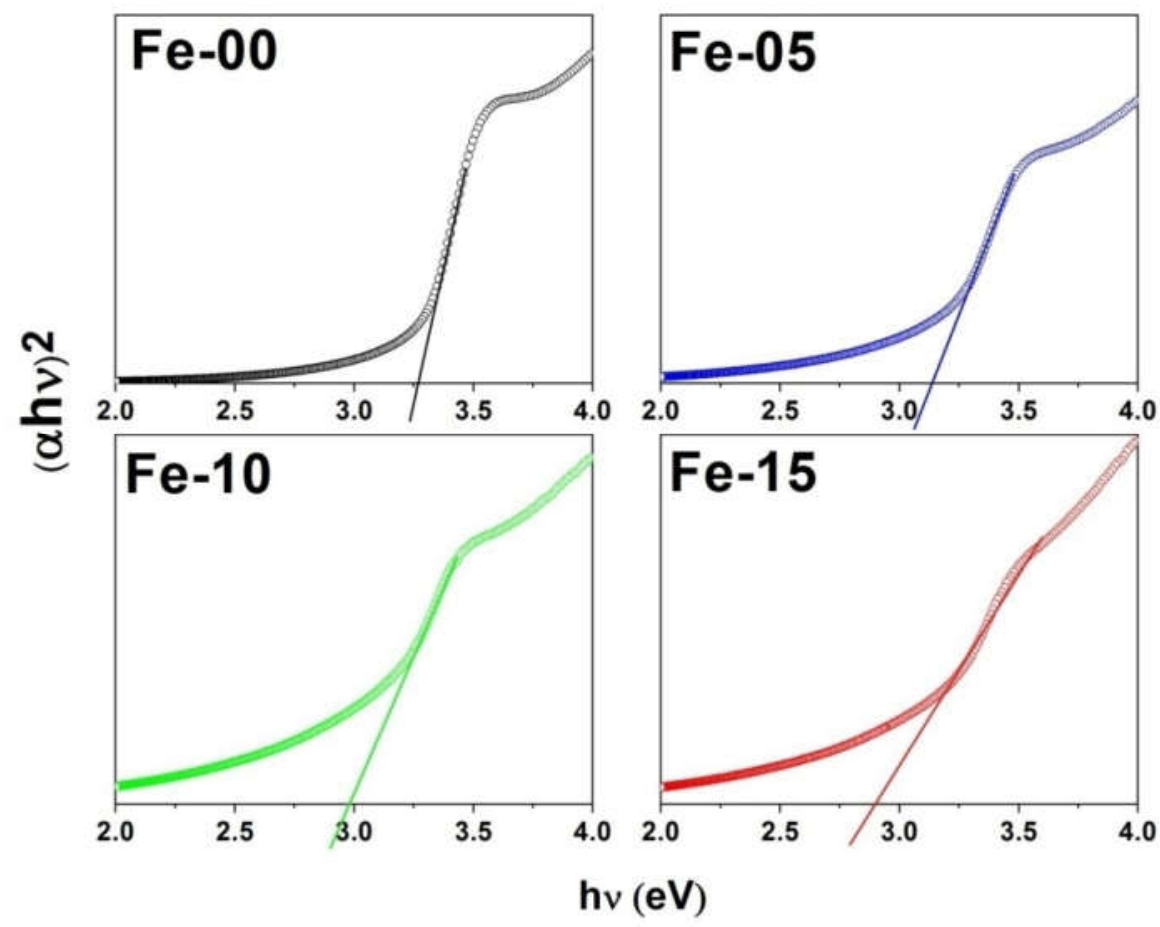

Figure 5

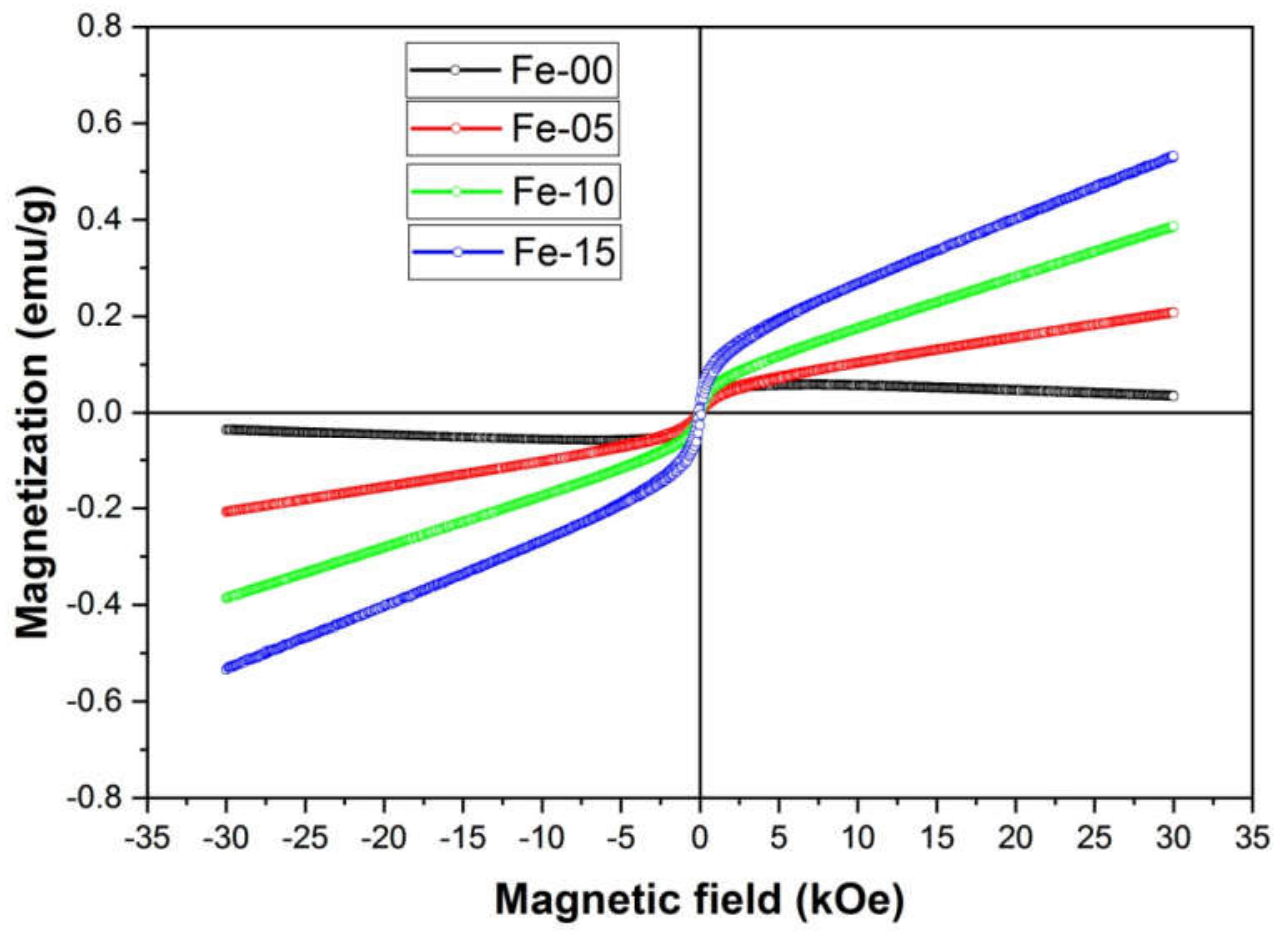

Figure 6 
Figures
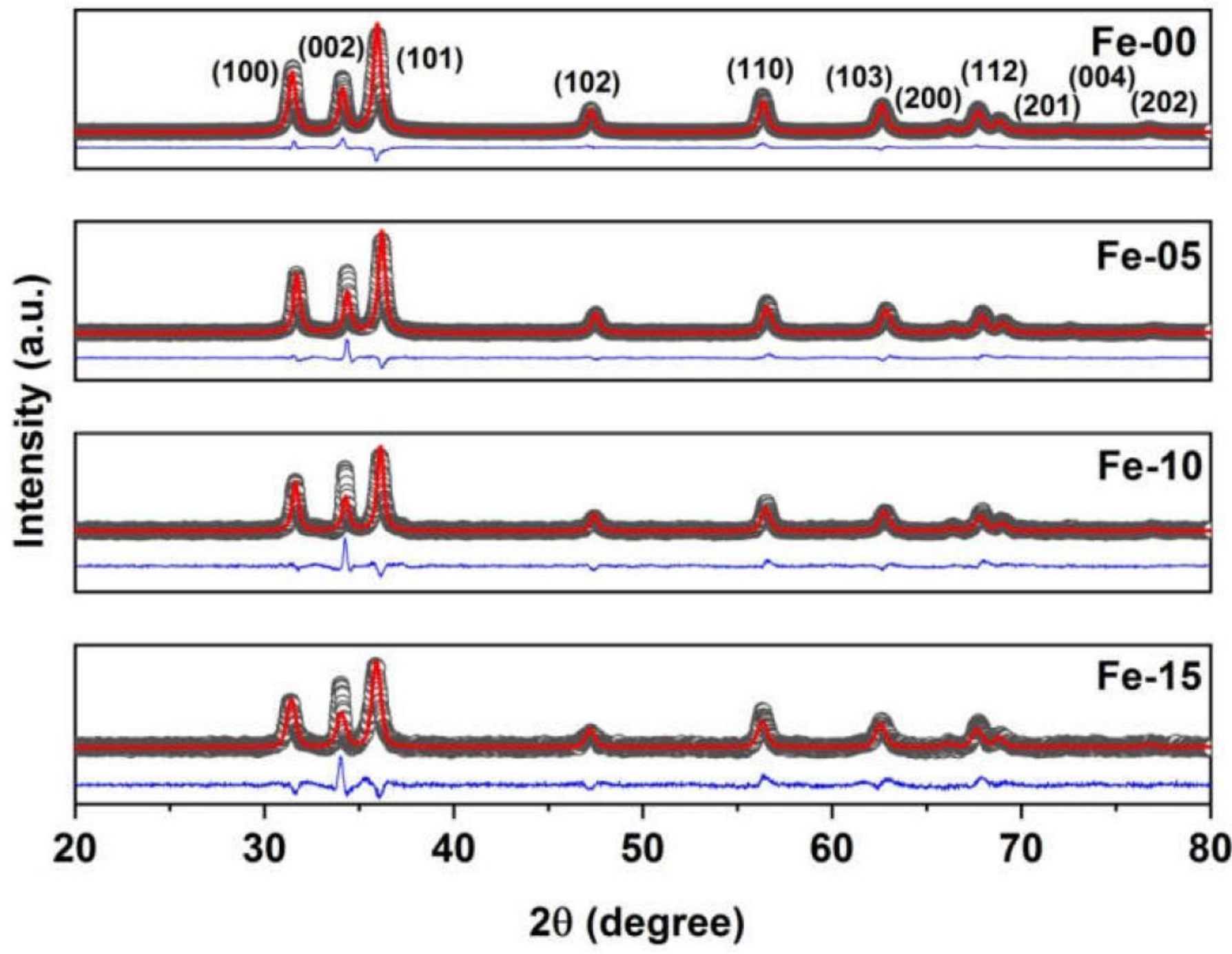

Figure 1

Fitted XRD profiles of Zn1-xFexO ( $x=0.00,0.05,0.10$ and 0.15$)$ samples. 


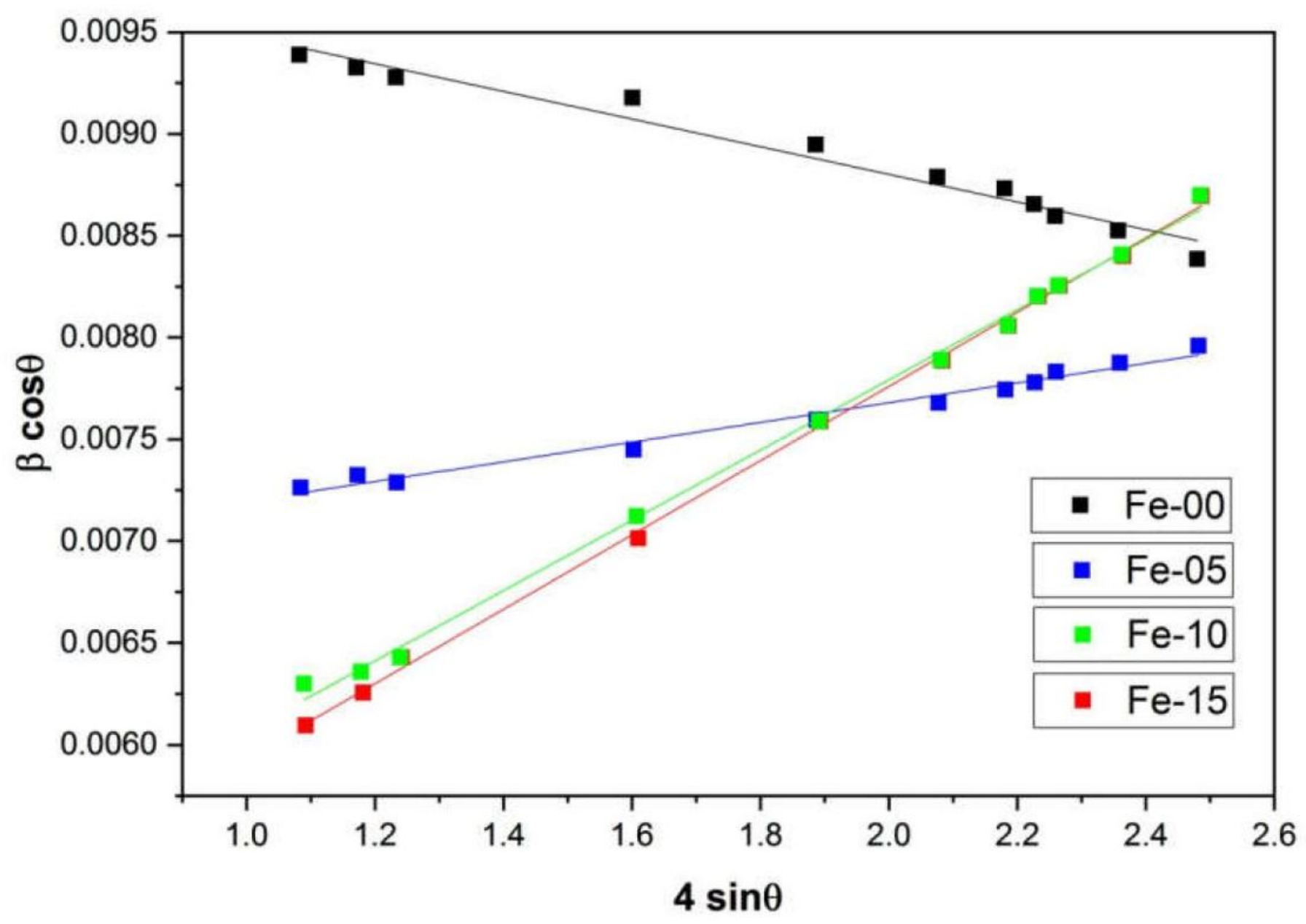

Figure 2

Williamson-Hall (W-H) plots of all the samples. 

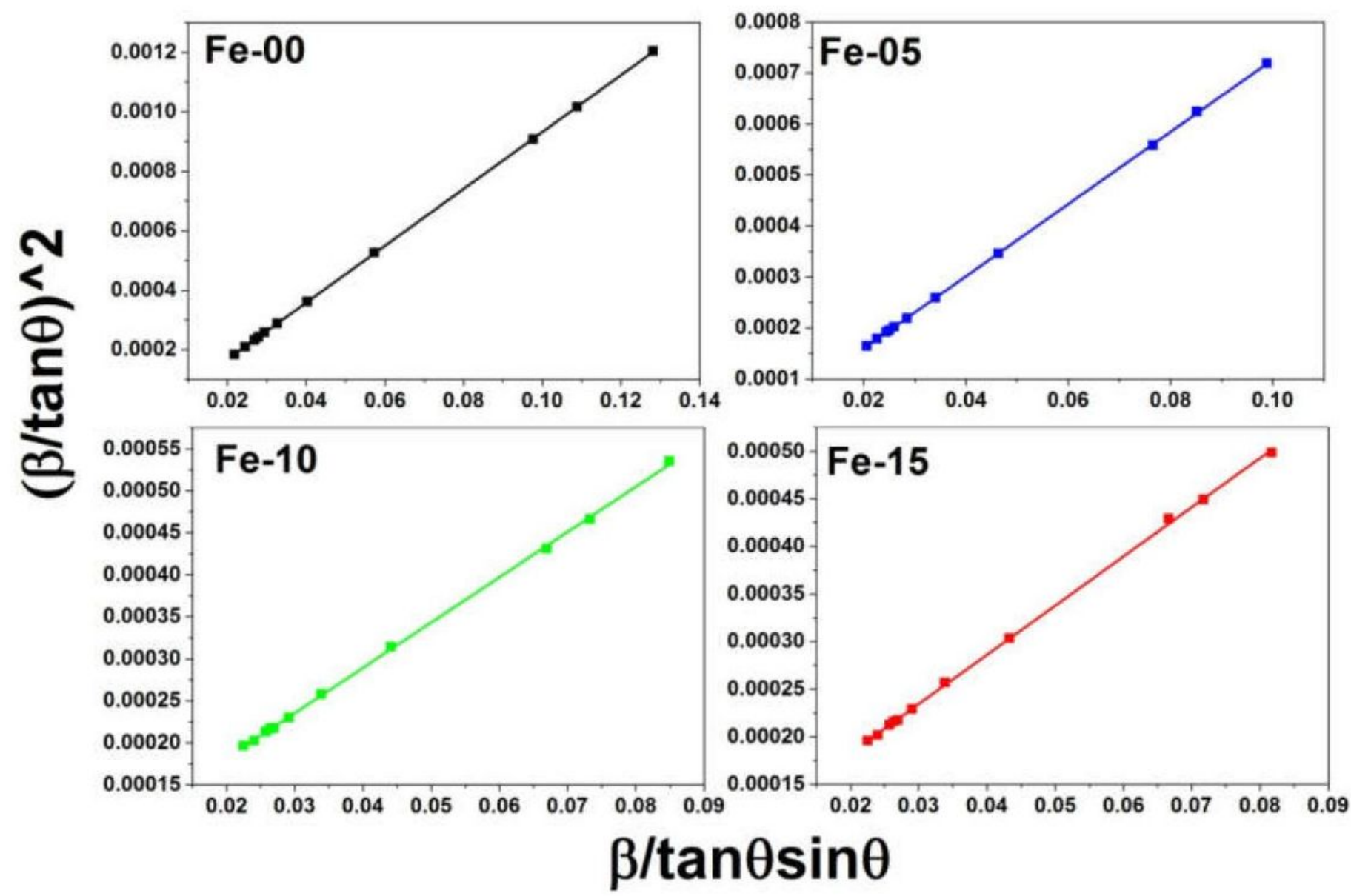

Figure 3

$\mathrm{H}-\mathrm{W}$ plots of all the samples. 


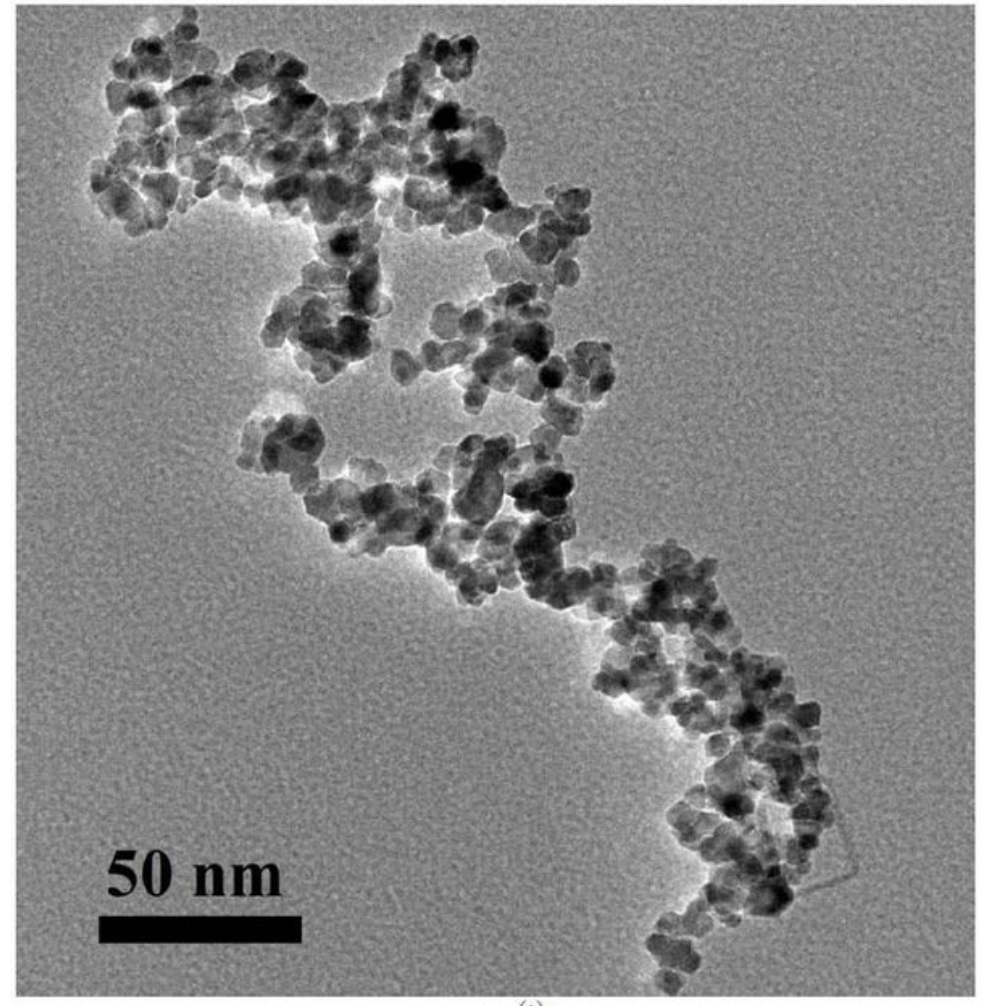

(a)

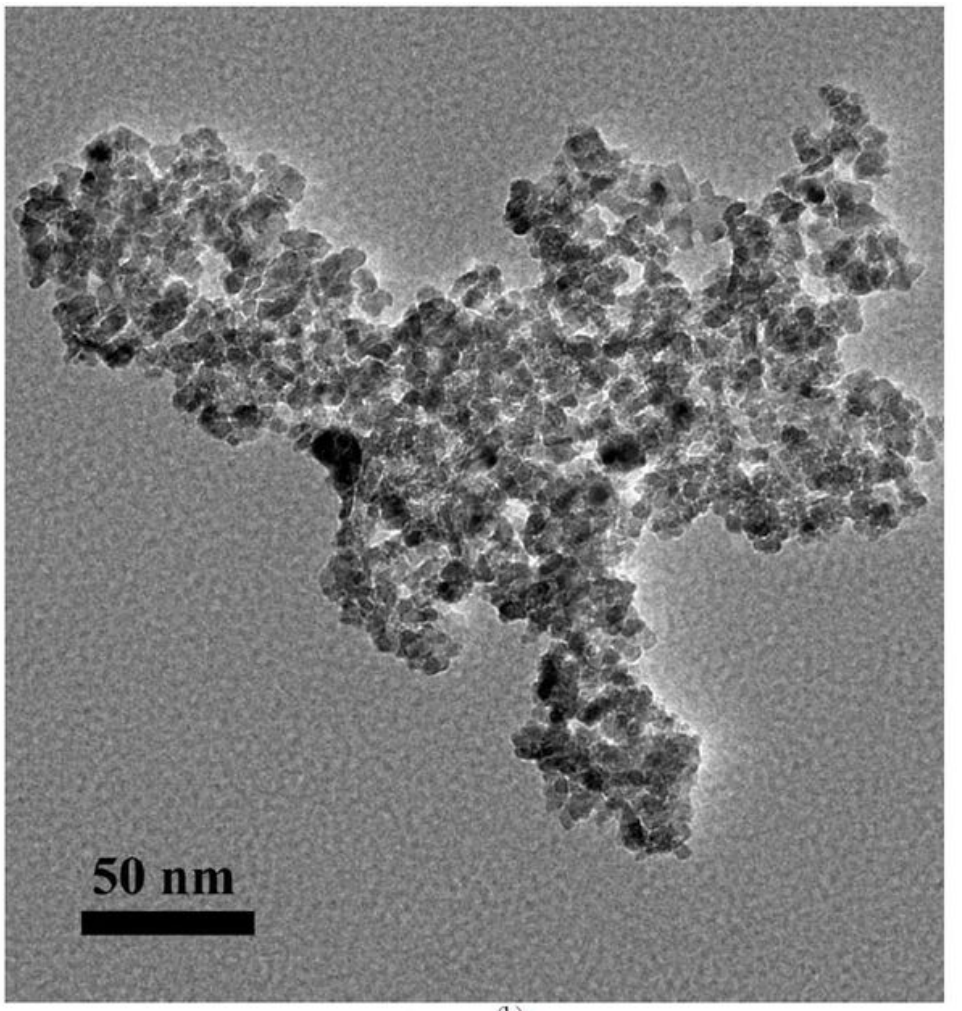

(b)

\section{Figure 4}

(a): HRTEM image of Fe-00 sample. (b): HRTEM image of Fe-10 sample. 


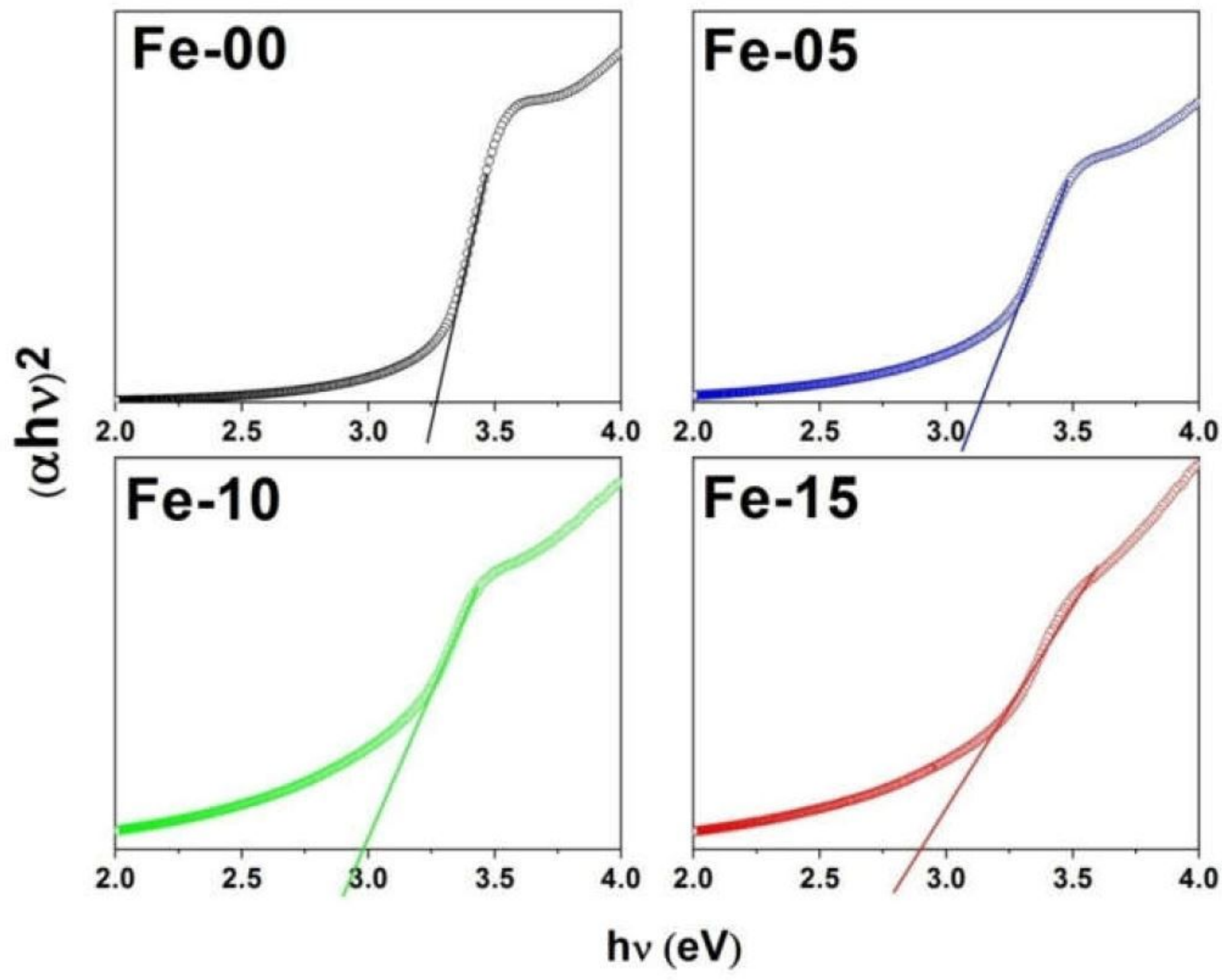

Figure 5

Tauc plot of all the samples. 


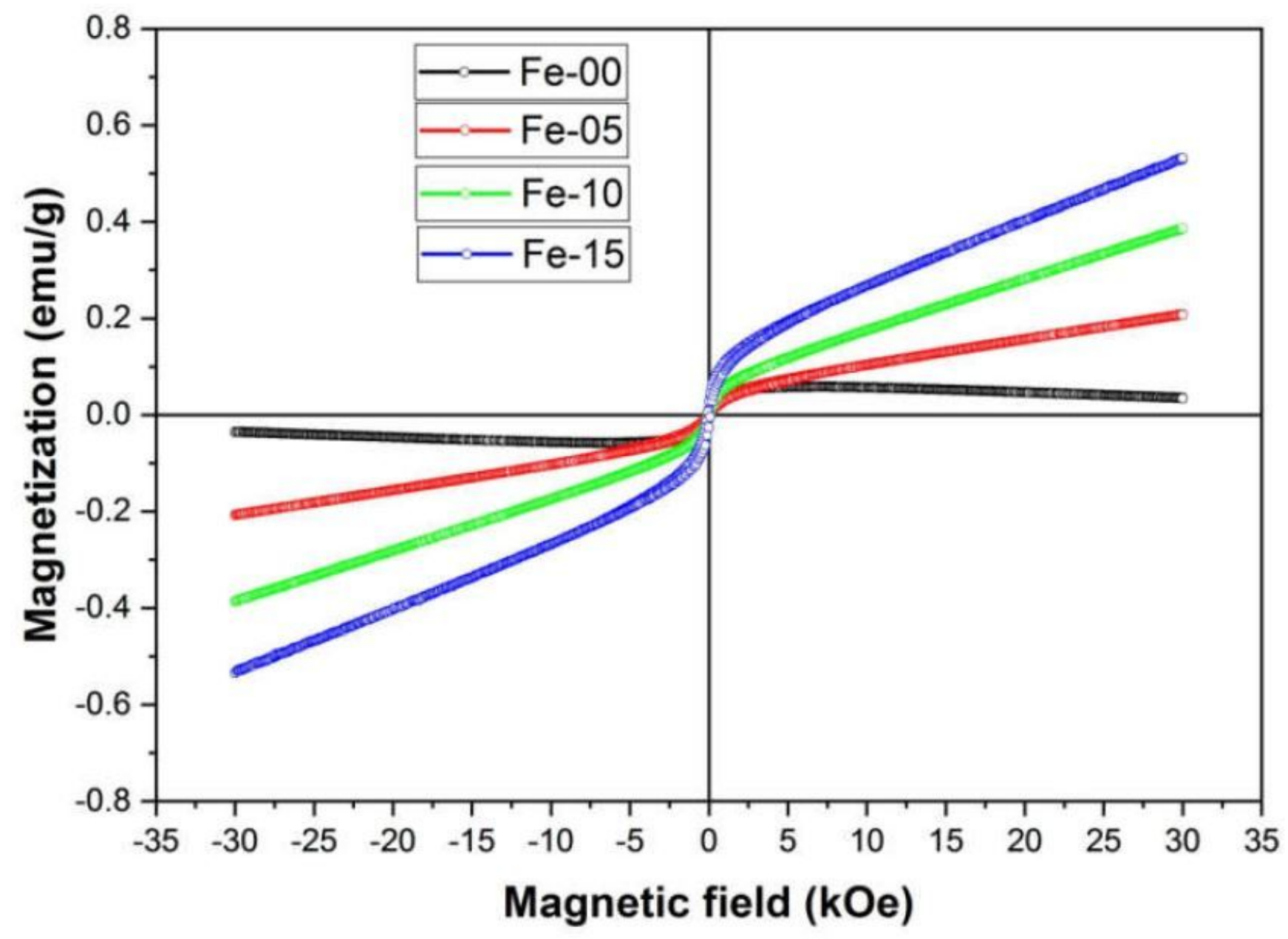

Figure 6

Room temperature $\mathrm{M}-\mathrm{H}$ plots of all the samples. 